\title{
Research Article \\ Study of Laparoscopic Repair Versus Laparotomy in Management of Peptic Perforation Peritonitis
}

\author{
Khetri $\mathbf{R}^{1}$, Dugar $D^{2}$, Khadanga $S^{3}$, Tim $H^{4}{ }^{4}$ Ghata $S^{5}$ \\ ${ }^{1}$ Dr. Ramji Khetri, Department of General surgery, ${ }^{2}$ Dr.Dharmendra Dugar, Department of General surgery, ${ }^{3}$ Dr. Sagar \\ Khadanga, Department of General Medicine, ${ }^{4}$ Dr. Tim Houghton T, PG Student, Department of General surgery, ${ }^{5}$ Dr. \\ Swarupjit Ghata, PG Student, Department of General surgery. All are affiliated to Hi-Tech Medical College and Hospital, \\ Bhubaneswar, Odisha, India.
}

Address for Corresponding: Dr. Tim Houghton T, Email: timhoughton@gmail.com

\begin{abstract}
Introduction: Despite the widespread use of antisecretory agents and eradication therapy, the incidence of perforated peptic ulcer has changed little. Since the initial reports of successful laparoscopic management of perforated duodenal ulcers and perforation peritonitis several larger comparative series have been published confirming the technical feasibility and advantages of laparoscopic approach. Objectives: The aim is to compare the outcome and efficacy of laparoscopic repair with conventional laparotomy in the management of peptic perforation. Methods: The study was conducted on patients with diagnosis of peptic perforation in Hi-tech medical college and hospital, Bhubaneswar. It is a retrospective and prospective study from September 2012 to April 2014. Result: 50 patients of peroration peritonitis were operated randomly by laparoscopic repair and laparotomy. It was found that the laparoscopic repair of perforated peptic ulcer was associated with less intra operative blood loss, no intra operative complications, minimum post operative complications, minimum postoperative pain which was significant as compared to laparotomy repair. Conclusion: Laparoscopic repair of perforated peptic ulcer could be considered as a treatment option in routine clinical practice in the management of peptic perforation peritonitis.
\end{abstract}

Key words: Laparoscopy, peptic ulcer, perforation.

\section{Introduction}

Acute perforation may occur in gastric and duodenal ulcers. It occurs in $5-10 \%$ of patients of peptic ulcer [1]. Duodenal perforation is a common complication of duodenal ulcer. Perforated duodenal ulcer is mainly a disease of young men as well as old age because of the use of NSAIDS for the treatment of painful conditions like arthritis. In the western society, there is increased incidence of perforated peptic ulcer because of smoking, alcoholism and use of NSAIDS. 75\% of patients of perforated peptic ulcers are helicobacter pylori positive. Perforated peptic ulcer is an emergency. During the past decade the need for elective operation for peptic perforation has decreased due to proton pump inhibitors. However, emergency operations for acute complications such as perforation or bleeding remain constant. Peritonitis caused by perforated peptic ulcer represents $3 \%$ of all abdominal emergencies. Surgical repair is the treatment of choice. The traditional approach is closure

Manuscript received: $24^{\text {th }}$ July 2014

Reviewed: 08 ${ }^{\text {th }}$ Aug 2014

Author Corrected: $14^{\text {th }}$ Sept 2014

Accepted for Publication: $17^{\text {th }}$ Sept 2014 of perforation with an omental patch i.e. Graham patch described in 1937 [2].

In 1989 Mouret performed first laparoscopic repair of perforated duodenal ulcer. Mouret was soon followed by Nathanson who in 1990 performed laparoscopic repair and peritoneal toilet $[3,4]$. In 1991 Costalet described laparoscopic repair of perforated gastroduodenal ulcer by using ligamentum teres hepatis. Since the initial reports of successful laparoscopic management of perforated duodenal ulcers and perforation peritonitis several larger comparative series have been published confirming the technical feasibility and advantages of laparoscopic approach.

\section{Aims and Objectives}

The aim to compare the outcome and efficacy of laparoscopic repair with conventional laparotomy in the management of peptic perforation based on the following parameters. 
1. Operative technique

2. Operative time

3. Analgesia required

4. Time till resumption of diet

5. Duration of nasogastric tube

6. Duration of ambulation from day of surgery

7. Hospital stay after surgery

8. Intraoperative and postoperative complications

9. Intraabdominal drain removal in days after surgery

10. Intraoperative blood loss in $\mathrm{ml}$

11. Duration of intravenous fluids for days after surgery

\section{Methodology}

The study was conducted on patients with diagnosis of peptic perforation in $\mathrm{Hi}$ tech medical college and hospital, Bhubaneswar. It is a retrospective and prospective study from September 2012 to April 2014. Consent was obtained from the patients and relatives. Ethical committee approval was taken. The study included a total of 50 patients with 25 patients in each group 1 and 2.

\section{Inclusion criteria}

1. Patients of both sexes

2. Patients $>15$ years of age $<70$ years

3. Patients with clinical diagnosis and radiological evidence of perforated peptic ulcer
4. No medical or surgical contraindication to general anaesthesia and laparoscopic surgery

\section{Exclusion criteria}

1. Complicated ulcers like bleeding ulcer, ulcer situated over posterior wall

2. Clinically sealed perforation

3. Patients with abdominal malignancy

4. Hemodynamically unstable (Systolic Blood pressure $<80 \mathrm{~mm} \mathrm{hg}$ )

5. Delay between onset of symptoms and presentation $>24$ hours

6. Patients with COPD, heart disease, coagulopathy, obesity, cirrhosis, advanced pregnancy

\section{Conversion criteria for laparoscopy to laparotomy}

1. Non juxtapyloric gastric ulcer

2. Ulcer $>10 \mathrm{~mm}$ in size

3. Technical difficulties

4. Concomitant haemorrhage

5. Hemodynamic instability during Laparoscopic repair

\section{Statistical analysis}

The results were interpreted as mean value. The parameters in both the groups were compared by unpaired t-test. Values were considered significant if $\mathrm{p}>0.05$.

\section{Result}

Table: 1. Comparison of blood loss, operating time and complications.

\begin{tabular}{|l|l|l|l|}
\hline & Group 1(Laparoscopy) & Group 2 (Laparotomy) & P Value \\
\hline Operating Time & 106 & 60 & 0.0021 \\
\hline Blood loss & 60 & 90 & 0.0009 \\
\hline Complications & 2 & 6 & \\
\hline
\end{tabular}

Operating time was 106 minutes in laparoscopy group 1 and 60 minutes in Laparotomy group 2. Blood loss was $90 \mathrm{ml}$ in Group 2 and $60 \mathrm{ml}$ in Group 1. [Table 1]

Table: 2. Comparison of various parameters between Group 1 and Group 2

\begin{tabular}{|l|l|l|l|}
\hline No. of days & Group1 & Group 2 & P Value \\
\hline Analgesic use & 1.2 & 3.8 & $<0.0001$ \\
\hline Resumption of food & 2.4 & 3.6 & 0.0391 \\
\hline Hospital stay & 9.4 & 9.8 & 0.7252 \\
\hline IV Fluid & 2.4 & 2.8 & 0.6395 \\
\hline Ryles tube & 3.2 & 3.2 & 1.0000 \\
\hline Ambulation & 2.4 & 3.4 & 0.0009 \\
\hline Drain & 2.2 & 3.8 & 0.0068 \\
\hline
\end{tabular}

Parentral analgesic requirement was 3.8 days in group 2 and 1.2 days in group $1(\mathrm{P}>0.05)$. Duration of nasogastric tube aspiration was 3.2 days with Group 1 and was 3.2 days in Group 2 as well. Resumption of normal diet was 2.4 days with 
group 1 and 3.6 days with group 2. Ambulation was in 2.4 days with group 1 and 3.6 with group 2. Intravenous fluid infusion requirement was 2.4 days in patients with group 1 and was 2.8 days in patients in group 2. Duration of intra abdominal drain in situ in group 1 was 2.2 days and in group 2 was 3.8 days. Duration of hospital stay for Laparoscopic repair was 9.4 days compared to 9.8 days for patients with laparotomy. [Table 2]

One case was converted from laparoscopy to laparotomy.

\section{Discussion}

There were 50 patients recruited, ages 16 to 70 years. The two groups were compared. Operating time was significantly longer in laparoscopy group (106 versus 60 minutes), which is comparable to other studies [3,4]. A possible explanation for longer operative time is that laparoscopic suturing is more demanding especially if the edges of the perforation are infiltrated and friable $[5,6]$.

Another reason for increase in operative time is the irrigation procedure. Irrigating through a $5 \mathrm{~mm}$ or even a $10 \mathrm{~mm}$ trochar is time consuming and suction of fluid decreases the volume of gas and reduces the pneumoperitoneum.

But the estimated blood loss is more in open surgeries 90 $\mathrm{ml} \mathrm{vs} 60 \mathrm{ml}$ in laparoscopic repair. This is because of the length of incisions, handling of tissues in contrast to minimal handling in laparoscopic repair [10].

After surgery patients in laparoscopic group required significantly less parenteral analgesics than those who underwent open repair (1.2 days in group 1 vs 3.8 in Group 2, $>>0.05$ ) which is statistically significant. It has already been proved that visual analogue pain scores on day 1 and day 3 after surgery were significantly lower in the laparoscopic group as well. The Meta analysis published by Lau showed that eight out of 10 studies showed significant reduction in dosage of analgesics required in laparoscopic group [7,8,11].

Mean duration of resumption of normal diet was 2.4 with laparoscopic repair and 3.6 with laparotomy. The reason for that is minimal bowel handling in laparoscopy produces less postoperative ileus and so patients tolerate oral feeding earlier $[10,11]$.

Mean duration of ambulation was 2.4 with laparoscopic repair and 3.6 with laparotomy. The reason for early ambulation is less post operative pain in patients with laparoscopic repair as compared to the large abdominal incisions employed in laparotomy $[10,11]$.

Mean duration of intravenous fluid infusion was 2.4 days in patients with laparoscopic repair and was 2.8 days in patients with laparotomy as patients of laparoscopic repair started tolerating oral feeds early and had less postoperative ileus $[10,11]$.

Mean duration of intra abdominal drain in situ in patients with laparoscopic repair was 2.2 days and in patients with laparotomy was 3.8 days. Minimal tissue handling results in less release of inflammatory factors like TNF, interleukins and has less postoperative drainage [11].

Mean duration of hospital stay for laparoscopic repair was 9.4 days compared to 9.8 days for patients with laparotomy. The values were significantly clinically and were an advantage of laparoscopic repair over laparotomy $[10,11]$.

There was one conversion from laparoscopic repair to laparotomy in a 70 year old male due to large size perforation and unusual nature of the perforated ulcer and need for biopsy. Clear advantages of laparoscopy are cosmetically better scar, less chances of chest infection which were not studied in our trial. European Association of Endoscopic Surgeons consensus statement states that Laparoscopy is clearly superior for patients with perforated peptic ulcer disease [9]. We believe that more randomised control trials are required before this statement can be fully supported.

\section{Conclusion}

In our study we operated 50 patients of peroration peritonitis randomly by laparoscopic repair and laparotomy. It was found that the laparoscopic repair of perforated peptic ulcer was associated with less intra operative blood loss, no intra operative complications, minimum post operative complications, minimum postoperative pain which was significant as compared to laparotomy repair.

On the other hand the operative time for laparoscopic repair was more as compared to laparotomy. The number of post operative complications was significantly more in laparotomy group. From the above observations we concluded that the laparoscopic repair of perforated peptic ulcer could be considered as a treatment option in routine clinical practice in the management of peptic perforation peritonitis. 
Funding: Nil

Conflict of interest: Nil

\section{Permission from IRB: Yes}

\section{References}

1. Naesgaard JM, Edwin B, Reiertsen O, Trondsen E, Faerden AE, Rosseland AR. Laparoscopic and open operation in perforated peptic ulcer. Eur J Surg. 1999 Mar;165(3):209-14.

2. Blomgren LG. Perforated Peptic Ulcer: Long-term Results after Simple Closure in the Elderly. World J Surg. 1997 May;21(4):412-4.

3. Mouret $\mathrm{P}^{1}$, François Y, Vignal J, Barth X, LombardPlatet R.. Laparoscopic treatment of perforated peptic ulcer. Br J Surg. 1990 Sep;77(9):1006.

4. F Charles Brunicardi, Dana K Andersen, Timothy R Billiar, David L Dunn, John G Hunter, Raphael E Pollock. Schwartz's Principles of Surgery. $8^{\text {th }}$ ed. McGraw-Hill Medical; 2004. P. 953-54, 957.

5. Nathanson LK, Easter DW, Cuschieri A. Laparoscopic repair/peritoneal toilet of perforated duodenal ulcer. Surg Endosc. 1990;4(4):232-3.

6. Schein M, Gecelter G, Freinkel W, Gerding H, Becker PJ. Peritoneal lavage in abdominal sepsis. A controlled clinical study. Arch Surg. 1990 Sep; 125(9): 1132-5.
7. Lau WY ${ }^{1}$, Leung KL, Kwong KH, Davey

IC, Robertson C, Dawson JJ, Chung SC, Li AK. A randomized study comparing laparoscopic versus ope $\mathrm{n}$ repair of perforated peptic ulcer using suture or sutureless technique. Ann Surg. 1996 Aug;224(2):131-8.

8. Sø JB, Kum CK, Fernandes ML, Goh P. Comparison between laparoscopic and conventional omental patch repair for perforated duodenal ulcer. Surg Endosc.1996 Nov; 10(11): 1060-3.

9. Sauerland S, Agresta F, Bergamaschi R, Borzellino G, Budzynski A, Champault G, Fingerhut A, Isla A, Johansson M, Lundorff P, Navez B, Saad S, Neugebauer EA. Laparoscopy for abdominal emergencies: evidence-based guidelines of the European Association for Endoscopic Surgery. Surg Endosc. 2006 Jan;20(1):14-29.

10. Ding J, Liao GQ, Zhang ZM, Pan Y, Li DM, Wang RH, Xu KS, Yang XF, Yuan P, Wang SY. Meta-analysis of laparoscopic and open repair of perforated peptic ulcer. Zhonghua Wei Chang Wai Ke Za Zhi. 2011 Oct;14(10): 785-9.

11. Bhogal RH, Athwal R, Durkin D, Deakin $\mathrm{M}$, Cheruvu CN. Comparison between open and laparoscopic repair of perforated peptic ulcer disease. World J Surg. 2008 Nov;32(11): 2371-4.

\section{How to cite this article?}

Khetri R, Dugar D, Khadanga S, Tim HT ,Ghata S. Study of Laparoscopic Repair Versus Laparotomy in Management of Peptic Perforation Peritonitis. Int J Med Res Rev 2014;2(5):487- 490. doi:10.17511/ijmrr.2014.i05.15 